\title{
EL RUFIÁN COBARDE: ¿EL PRIMER FANFARRón DEL TEATRO ESPAÑOL DEL XVI? ${ }^{1}$
}

\author{
Josef PROKOP \\ Universidad de Bohemia del Sur de České Budějovice
}

\begin{abstract}
En): If we look for the representations of the old theatrical type of the braggart soldier in the Spanish theatre of the $16^{\text {th }}$ century, we soon discover that practically no Spanish avatar of the type corresponds completely to the numerous examples of the ancient Greco-Roman archetype. However, it is possible to find several characters who, although they do not comply with all the tiny nuances of the characteristics, approach the said archetype in many points. In the theatre of the sixteenth century the character of Sigüenza of the short play El Rufián cobarde written by Lope de Rueda could be the first of them. Extracted the absence of boasting about conquests of women, typical for a braggart, but unnecessary for a character with features of ruffian, Siguienza is presented as one of the perfect and crystalline realizations of the archetype. And this is not little to affirm, considering the complexity of the modifications that the characters of the theatre of the $16^{\text {th }}$ century present to us.
\end{abstract}

Key words (En): braggart soldier; El Rufián cobarde; Lope de Rueda; theatrical archetype; alazón

Palabras claves (Es): soldado fanfarrón; El Rufián cobarde; Lope de Rueda; arquetipo teatral; alazón

Si tratamos de analizar en el teatro español del siglo XVI las representaciones del antiguo tipo teatral del «soldado fanfarrón», conocido ya en el antiguo teatro griego, desde el principio observamos una característica prototípica. Como ya hace tiempo advirtió María Rosa LIDA DE MALKIEL (1957), prácticamente ningún personaje de las tablas españolas que suele ser considerado como soldado fanfarrón - comenzando desde Centurio de la Tragicomedia de Calisto y Melibea (1502) corresponde de manera completa con los protagonistas del teatro grecolatino. ${ }^{2}$ Es decir, en las tablas españolas encontramos muy pocos personajes (o prácticamente ninguno, dependiendo del rigor con el cual apliquemos las definiciones) que cumplan con todas las características pormenorizadas que los investigadores modernos han extraído de los comediógrafos grecolatinos. Lo que encontraremos son variantes que solamente se acercan a dicho arquetipo en un aspecto, en algunos aspectos o en muchos puntos, pero con ausencia de un rasgo fundamental. De ahí,

\footnotetext{
${ }^{1}$ Artículo publicado con el apoyo de la Fundación Científica de la República Checa (Czech Science Foundation), proyecto GA19-16481S «Transformaciones del personaje literario y teatral del soldado fanfarrón en Francia, Italia y España del siglo XVI y XVII». Tento článek vznikl v rámci projektu GA19-16481S s názvem «Proměny literární a jevištní postavy chlubivého vojáka ve Francii, v Itálii a ve Španělsku 16. a 17. století», podporovaného Grantovou agenturou České republiky.

${ }^{2}$ El representante más famoso será probablemente Pyrgopolinices del Miles gloriosus plautianosin embargo, pero los comediógrafos grecolatinos han creado numerosos ejemplares del tipo. En los fragmentos de Menandro de Misoumenos encontramos a Bias en Colax a Thrasonides. Plauto creó, junto al mencionado Pyrgopolinices, personajes como Cleomacus en Bacchides, como Antamonides en Poenulus, como Stratophanes en Truculentus y como Polymachaeroplagides en Pseudolus. Y de Terencio fue muy conocido el personaje Thraso de la pieza Eunuchus. Cfr. la lista extensa de BOUGHNER (1943 : 44-48).
} 
viene la necesidad de precisar tanto la definición del tipo para el teatro español del XVI como los posibles candidatos que puedan representarla. Una incitación que todavía pocos estudiosos han aceptado.

Por lo tanto, el objetivo del presente estudio es emprender el camino en esta dirección y presentar un análisis detallado de un posible representante del arquetipo. Un representante que podría servir de paradigma para otros avatares por dos razones. Por un lado, porque le caracteriza la perfección con la cual se asemeja a las definiciones del tipo, y por otro por ser cronológicamente uno de los primeros personajes que aparecen de esta forma. Trataremos de ejemplificar su caso comparando las características del personaje seleccionado con las definiciones de dicho arquetipo. Nos parece obvio que toda la valoración de cumplimiento o no de los rasgos que delimitan el tipo siempre es subjetiva. No obstante, trataremos de hacerlo con un acercamiento lo más imparcial y analítico posible. Además, quizás pueda parecer este enfoque demasiado superfluo e irrelevante para el conocimiento del teatro áureo por su limitación a un personaje concreto de una concreta pieza. Sin embargo, nosotros creemos que semejante acercamiento analítico es un método sumamente efectivo para tratar el tema. A la hora de poseer las características minuciosamente investigadas del más número posible de variantes del fanfarrón, estas luego servirán para deducir de ellas una característica general del tipo (por lo menos, para el periodo estudiado del siglo XVI).

Enfocaremos así nuestro análisis en el personaje de Sigüenza, que aparece en un breve paso de Lope de Rueda, y que reúne en sí mismo (casi) todas las características del tipo establecidas por las definiciones. Sigüenza será así un caso opuesto al curioso personaje de Golondrino (de un entremés anónimo del siglo XVI) que ya hemos estudiado en otro lugar, el cual aparentemente podría también enlistarse entre las numerosas variantes fanfarronescas del teatro español, pero en el cual faltan prácticamente todas la características que definen al tipo. ${ }^{3}$

Empecemos con las definiciones del arquetipo. Aunque las fechas podrían parecer ya anticuadas, nosotros consideramos como todavía vigentes las definiciones del soldado fanfarrón que propusieron dos excelentes estudiosos del teatro europeo. Primero J. P. Wickersham CRAWFORD (1911 : 188) quien en un artículo particular esbozó una delimitación para el tipo en el antiguo teatro grecolatino (conectándolo con su reaparición en el siglo XVI). Y su propuesta fue utilizada y modificada por Daniel C. BOUGHNER (1940 : 213) para el campo del teatro italiano, inglés y español del periodo áureo. Como una reacción al libro

\footnotetext{
${ }^{3}$ Entremés entre un muchacho llamado Golondrino y de dos amigos suyos Garnica y Zaballos, y de Doña Calandria, amiga del Golondrino, y de Biçente Aragones, Rufian, y de Angela Çamorana, amiga del Rufian. Se trata de un ms. de 3 hojas en cuarto conservado en la Biblioteca Nacional de España, fechable por su escritura al final del siglo XVI, que fue modernamente editado por G. L. LiNCOLN (Golondrino y Calandria: An inedited entremés of the Sixteenth century, Romanic Review, 1 (1), 1910, p. 41-49) y casi inmediatamente incluido por COTARELO Y MORI en su colección de entremeses (Colección de entremeses, loas, bailes, jácaras y mojigangas desde fines del siglo XVI a mediados del XVIII, ordenada por Don Emilio Cotarelo y Mori de la RAE, tomo I, volumen I, Madrid, Casa editorial Bailly et Baillière, 1911, p. 76-79). Nuestro estudio al que aludimos es PrокоP, 2018. Se puede complementar con un panorama más general, en el cual esbozamos precisamente la necesidad de modificar la definición del miles gloriosus para los protagonistas del teatro español de los siglos XVIXVII (PROKOP, 2019).
} 
sintético de BOUGHNER (1954) que precisamente resume el tema, surgió el ya mencionado artículo-reseña de María Rosa LIDA DE MALKIEL (1957), en el cual se precisan varios detalles de definiciones precedentes y se establece, por lo menos desde nuestro punto de vista, la propuesta final y acabada - hasta hoy en día - para definir todas las características muy particulares del soldado fanfarrón en el teatro español de los siglos XVI-XVII. No nos consta que en el debate científico posterior surgiera otra propuesta de definición tan compleja y tan completa de este particular tipo teatral. ${ }^{4}$ Resumiendo las observaciones de los tres citados especialistas, podemos afirmar las características delimitativas del fanfarrón así :

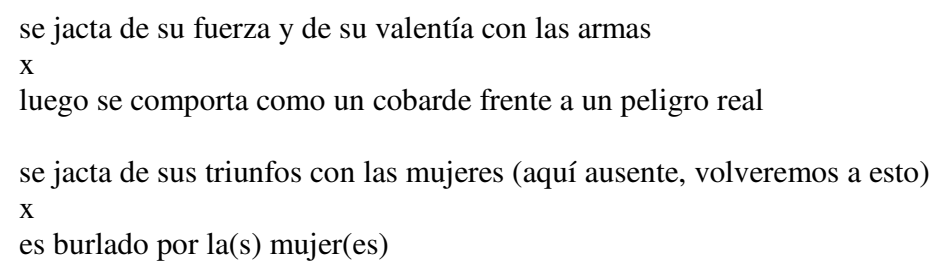

El sujeto de nuestro análisis, como ya se ha adelantado, será el personaje de Sigüenza del poco complicado paso de Lope de Rueda que en las ediciones de Moratín y de Cotarelo es denominado como El rufián cobarde. Conocemos el texto de su publicación dentro del antológico Registro de representantes imprimido por Timoneda en 1570 en Valencia ${ }^{5}$, en el cual lleva la cabecera siguiente: «Muy gracioso [paso] agora nuevamente compuesto por Lope de Rueda; introducense en él las personas siguientes: Sigüenza, lacayo, Sebastiana, mundana, Estepa, lacayo...» (Registro de representantes, 1917 : 113). Debido a que no se han relevado hasta el momento datos más precisos, podemos suponer solamente la redacción y

\footnotetext{
${ }^{4}$ No hemos encontrado otros estudios enfocados concretamente al arquetipo del soldado fanfarrón que los ya mencionados de CRAWFORD, BOUGHNER y LIDA DE MALKIEL (junto con inspirativo, pero ya un poco anticuado libro de SENIGAgLia de 1899) y los más modernos trabajos de VILANI (1965) y DE Michele (1999). En cuanto a otros, Tiziana Mazzucato dedicó un estudio al arquetipo (2007), pero su interés apunta hacia cuestiones de la transgresión del fanfarrón teatral en la narrativa. Por otro lado, María José MARTínez LóPEZ en su docto libro (1997), surgido de su tesis doctoral, propone un interesante panorama de los protagonistas del entremés no pudiendo evitar los tipos frecuentes como valientes o valentones, soldados (no necesariamente fanfarrones), caballeros ridículos y jactanciosos etc. Estas bellas páginas contribuyen de manera interesante a la discusión de la índole del fanfarrón, no obstante, no tratan a nuestro tipo de manera detallada. También se acerca a él Antonio SÁNCHEZ JIMÉNEZ en sus artículos (2007 y 2012) en los cuales llega a importantes observaciones sobre el tipo fanfarronesco visto por la perspectiva particular de la imagen literaria de García Paredes (el «Sansón de Extremadura»). Y no podemos no mencionar algunas obras de la avivada discusión científica sobre el «figurón», un tipo teatral estrechamente relacionado con el nuestro, que abordan también el tema del fanfarrón como las de Olga Fernández FernándeZ (2003/1999) o de Antonio Moreno HERNÁNDEZ (2007).

${ }^{5}$ Registro de Representantes, Valencia, 1570 que contiene seis pasos, de los cuales los tres últimos están explícitamente atribuidos a Lope de Rueda (cfr. Registro de representantes, 1917 : X). Según Bonilla y San Martín se conoce también una edición anterior de 1570 que constaba de 32 hojas (ib.). Sus primeras ediciones modernas son de FERNÁNDEZ de Moratín (1830) de CotARElo y Mori (1911) y de Bonilla y SAN MARTín (Registro de representantes, 1917). Desgraciadamente no hemos podido consultar le edición de Cotarelo y Mori de Pasos completos (LOPE DE RuEdA, 1908). Entre las ediciones más recientes trabajamos con la prologada por García Pavón (LOPE DE RUEDA, 1981).
} 
las representaciones del paso en el periodo de la actividad teatral de Rueda, es decir desde 1540 hasta su muerte en 1565 (DIAGO, 1990 : 53-54).

En cuanto a las cuestiones cronológicas, en el texto encontramos una alusión bastante curiosa a un año concreto, el de 1546 (el texto nos da incluso la fecha exacta del 9 de abril, FERNÁNDEZ DE MORATÍN, 1830 : 432), en el cual debía acontecer una fanfarronada referida por el protagonista en la pieza. Este dato nos podría sugerir una indicación para la ubicación temporal de la pieza. No obstante, la consideramos muy problemática, puesto que hay varias posibilidades de cómo interpretar esta última mención. ¿Deberíamos entenderla como una fecha post quem? ¿O se trata de una alusión variable en la pieza que debía ser actualizada para el público en diversas representaciones? ¿O estamos ante una interpolación del editor de la pieza?

De todos modos, constatemos que el año 1546 se ubica perfectamente en el periodo señalado de la actividad teatral de Lope de Rueda y, por lo tanto, no contradice la presuposición anterior.

¿Cuáles son entonces las características particulares del personaje de este paso que apuntarían hacia su relación con la definición del arquetipo mencionada anteriormente? Empezando con el rasgo de su jactancia de valentía con las armas podremos comprobar que Sigüenza cumple casi perfectamente con las exigencias de este rasgo particular. Recordemos que en las otras apariciones del tipo en el teatro español estos personajes ni siquiera se conectan dentro del mundo de la pieza con el uso de armas, duelos o batallas (directamente representado o verbalmente referido) y su carácter «militar», o más bien matón, queda insinuado sobre todo por sus amenazas verbales a otros protagonistas, y por ostentación de una espada u otra arma. Pensemos en Centurio de la Tragicomedia, aludido ya a principio de estas líneas, el primogénito español de este personaje tipo que nos da un buen ejemplo. El caso de Sigüenza es diferente y en el texto encontramos importantes pasajes que le asocian con las características del arquetipo fanfarronesco, aunque manteniendo la distancia de una explícita mención de la actividad militar.

En las primeras réplicas del paso, el mismo Sigüenza cuenta a su amiga los pormenores de una «escaramuza» acaecida en Mallorca (supuestamente real, volveremos a esto) de la cual salió victorioso. Como es natural, Sigüenza hiperboliza la descripción, de tal manera que estamos convencidos de que ni el auditorio de los tiempos de Rueda ni el espectador actual pueden tener dudas de que lo referido sobrepasa los límites de la credibilidad llegando hasta lo cómico, precisamente, como lo dicta el carácter del arquetipo. De esta manera, Sigüenza explica a su amiga Sebastiana las circunstancias en las cuales perdió sus propias orejas (un castigo frecuente en la justicia de su tiempo):

«SIGÜENZA. En el año de quinientos y cuarenta y seis, á nueve dias andados del mes de abril (la cual historia se hallará hoy en dia escrita en un tabla de cedro en la casa del ayuntamiento de la isla de Mallorca), habiendo yo desmentido á un coronel natural de Ibiza, y no osándome demandar la injuria por su persona, siete soldados suyos se convocaron á sacarme al campo, los nombres de los cuales eran (Dios les perdone) Campos, Piñeda, Osorio, Campuzano, Trillo el cojo, Perotete el zurdo, y Janote el desgarrado; los cinco maté, y los dos tomé á merced.

SEBASTIANA. ¡Válame Dios qué gran hazaña! Mas las orejas dime, señor, ¿cómo las perdiste? 
SIGÜENZA. A eso voy: que viéndome cercado de todos siete, por si acaso viniésemos a las manos no me hiciesen presa en ellas, yo mismo (usando de ardid de guerra) me las arranqué de cuajo, y arrojándoselas a uno que conmigo peleaba, le quebranté once dientes de golpe, y quedó torcido el pescuezo, donde al catorceno dia murió, sin que médico ninguno le pudiese dar remedio.» (FERNÁNDEZ DE MORATÍN, 1830 : 432-433)

La jactancia desfrenada de las palabras de Sigüenza en la segunda réplica, típica del fanfarrón, nos parece tan obvia que no necesita explicaciones. Señalemos que a ella se unen otros pasajes de la pieza que presentan otros momentos de jactancia del protagonista que son menos intensos, pero bien podrían confirmar el tono del pasaje aludido. A través de ellos, consideramos la primera característica mencionada del tipo fanfarronesco suficientemente documentada en la obra.

No obstante, agreguemos que en la búsqueda de los límites exactos de la definición del fanfarrón, todavía hay algunos matices a los que ya hemos aludido y que tenemos que precisar. A saber, hay que distinguir entre la jactancia, cuya exageración es obvia desde el primer momento para el auditorio (y muchas veces incluso para otros personajes de la pieza como sucede en el pasaje que acabamos de citar). En particular en el Miles gloriosus plautiano son los propios parásitos del protagonista los que hacen ensalzar las hazañas de su benefactor con tal grandiosidad, que queda fuera de lo creíble. Por ejemplo, cuando le atribuyen al protagonista centenares de muertos en un día. ${ }^{6}$ Sin embargo, por otro lado, a veces oímos de la boca del fanfarrón jactancias que, a pesar de toda la exageración, nos pueden parecer posibles, por lo menos, a primera vista. Pensemos en el aquí citado duelo con los siete oponentes referido por Sigüenza. A nuestro parecer, este podría pertenecer a dicha categoría. Incluido hasta su sorprendente resultado «los cinco maté, y los dos tomé á merced», el cual no rebasaría los límites de la inverosimilitud. Claro, si extrajéramos de la suma los dientes rotos y la muerte causada por un simple lanzamiento de las orejas.

Podríamos así distinguir entre las batallas victoriosas de ejércitos enteros que nos cuenta el parásito de Pirgopolinices (y otros similares pasajes de los grecolatinos) y entre una «escaramuza» descrita de una manera hiperbólica, eso sí, pero cuyo fundamento real - una pelea armada de uno contra siete - podría ser creíble a fin de cuentas.

De todas formas, la cuestión de la credibilidad o incredibilidad de la jactancia fanfarronesca tal como se representa en el teatro es una distinción muy sutil que no podemos desarrollar más en este momento. Por lo tanto, solamente constatemos que nuestro protagonista demuestra muy de sobras la jactancia militar de acuerdo con la definición del tipo.

\footnotetext{
${ }^{6}$ Para ilustrar citemos un pasaje concreto del Miles gloriosus (fijémonos también en el nombre del país inventado y en el cálculo distorsionado): «Artotrogo. Sí, seňor: ciento cincuenta en Cilicia, cien en Escitolatronia, treinta sardos y sesenta macedonios son los hombres a los que diste muerte en un solo día. Pirgopolinices. ¿Cuántos hacen en total? Artotrogo. Siete mil. Pirgopolinices. Ni más ni menos. La cuenta es exacta.» Plauto Tito Macio (1996), Comedias II, Madrid, Gredos, p. 312-313.
} 
A propósito de la pelea mencionada, debemos detenernos en otra cuestión que es aparentemente menor pero, sin embargo, de suma importancia para nuestro tipo. Deberíamos preguntarnos si la pelea de Mallorca (real o inventada) referida por el personaje implica o no que Sigüenza fuera un soldado real en aquel momento. Puesto que esto modificaría considerablemente la característica del protagonista, declarado en los preliminares de la pieza como un lacayo, pero evocada su carrera de ladrón profesional («carterista», diríamos hoy) algunas réplicas más abajo (FERNÁNDEZ DE MORATín, 1830 : 433-434). Así que debemos plantearnos la cuestión fundamental de que si consideramos la citada historia de la riña de Sigüenza con siete como una fabulación suya o no. Lo primero parecería muy probable ya que el protagonista la cuenta para ocultar las circunstancias reales y verídicas (dentro de la ficción escénica) en las que perdió ambos oídos. No quisiéramos caer en una tautología afirmando que Sigüenza es fanfarrón porque se comporta como un fanfarrón, puesto que interpretamos sus hechos y dichos como fanfarronadas. Pero nos parece que las injurias que supuestamente pronunció la amiga del rufián Estepa, el antagonista de Sigüenza, las cuales las oímos referidas por Sebastiana diciendo que a Sigüenza le cortaron las orejas por castigo $^{7}$, la incredulidad de ella y la manera con la cual Sigüenza trata de refutar la acusación, nos parecen claves suficientes que nos permiten interpretar su exagerada descripción de la «batalla» como una defensa fabulada. Es decir, que los personajes de Sigüenza y Sebastiana reconocen que lo dicho por la amiga de Estepa (que Sigüenza perdió las orejas por castigo) es verdad, pero no pueden aceptarlo desde la perspectiva de su «honra» personal y así tratan de negarlo y fingir otra explicación.

¿Descarta, no obstante, todo esto la existencia de una escaramuza en Mallorca en el mundo de ficción del paso? No necesariamente, nos parece. Después de todo, es posible que la riña haya tenido lugar, aunque con mucha probabilidad con un resultado diferente del que Sigüenza modificara para sus fines propios. Por lo menos, ninguna información aducida en la pieza lo excluye. Y por lo tanto, si el protagonista peleara con un «coronel natural de Ibiza» en Mallorca y si fuera después atacado por «siete soldados suyos», ¿no sería lógico pensar que el mismo Sigüenza estuviera allí en calidad de soldado, moviéndose en contacto con otros soldados y su coronel? Por supuesto, con tal interpretación Sigüenza aparecería como un caso bastante raro entre los fanfarrones teatrales del periodo del cual hablamos. Como un verdadero soldado o veterano de guerra, quedaría fuera del dominante grupo de fanfarrones españoles que no tienen ninguna conexión real con el mundo de la milicia (otra vez pensemos a Centurio, a sus análogos de la comedia erudita y a la mayoría de otros avatares del tipo).

Pero por otro lado, si consideramos como delimitativos para su caso su supuesto anterior pasado militar transformado en su presente oficio de ladrón, Sigüenza encajaría bien en una categoría que podríamos suponer (aunque no siempre

\footnotetext{
7 «SEBASTIANA. Y amenazándola yo contigo, me dijo: váyase el ladron desorejado... SIGÜENZA. Qué, ¿tal osó decir? ¡ah Dios! ¿y cómo se hunde la tierra? SEBASTIANA [refiriéndose a lo que había dicho Estepa]. Que si no se huyera de la carcel, como se huyó, le hicieran escribano Real, y le pusieran en la mano una péndola de veinte y cinco palmos.» (FERNÁNDEZ DE MORATín, $1830: 431$ ).
} 
confirmar con datos explícitos de las piezas) entre algunos de los fanfarrones de las tablas españolas de este tiempo, la característica de un «soldado arrufianado». Carrera que habrían podido compartir con él precisamente varios de los aludidos fanfarrones de las eruditas. Es bien sabido que una de las formas frecuentes de ganarse la vida para un español del siglo XVI era la milicia. Y como los hombres habitualmente eran reclutados ad hoc para una acción militar específica, los profesionales muy a menudo se encontraban en inactividad entre una campaña y otra. En aquellos momentos, pudieron buscarse medios de subsistencia de una manera diferente y, lógicamente, dada su experiencia con las armas, podían convertirse en «matones» profesionales o bien en «rufianes», a cuyo «oficio» eran inherentes las capacidades de matón.

Volviendo al texto estudiado, sin embargo, es necesario tener siempre bien presente que este supuesto pasado militar de Sigüenza nunca es declarado explícitamente, y solo puede deducirse especulativamente tal como lo hemos hecho. Con lo cual, contrasta que el mismo Sigüenza se jacte de ser un ladrón carterista como vimos. Es decir, en la pieza se menciona explícitamente que el protagonista es un ladrón, pero no se dice explicite que él fuera o hubiera sido un soldado. Y todo esto a pesar del episodio referido de la escaramuza de Mallorca, puesto que permite varias interpretaciones.

Abordemos ahora el segundo elemento de la definición fanfarronesca, esto es la jactancia de éxitos mujeriegos, que en el estudiado paso ruediano tiene mucho que ver con lo que acabamos de decir. Si consideramos a Sigüenza (aunque formalmente llamado «lacayo» en los preliminares de la pieza en su primera edición) como un rufián o un ex-soldado arrufianado, por las específicas relaciones con las mujeres que se derivan de este oficio particular, él consecuentemente perdería una de las características típicas del miles gloriosus grecolatino. Esto es la jactancia de triunfos amorosos, los cuales son totalmente irrelevantes para un rufián, un «manager» de mujeres públicas. Nos parece que este precisamente es el caso de nuestro personaje, puesto que en todo el paso, no encontraremos ni una sola mención relevante de este tipo de jactancia, ni siquiera distante y pasajera. En el pequeño espacio del paso, ni Sigüenza ni otros personajes aluden a otras mujeres vinculadas con él. Más bien al contrario, Sigüenza repetidamente manifiesta su cariño y lealtad hacia su amiga (declarada como «mundana» en los preliminares, no olvidemos), igual que la voluntad de defender el honor de su «dama». Lo comprobamos en el siguiente pasaje:

«SIGÜENZA. Pasa delante, señora Sebastiana, y cuéntame por extenso, sin poner ni quitar tilde, del arte que te pasó con esa piltraca disoluta, amiga dese antuviador de Estepa, que yo te la pondré de suerte que tengan que contar nascidos y por nascer de lo que en la venganza por tu servicio hiciere.

SEBASTIANA. Qne no, sino cuál hinchiria su cántaro primero á la fuente, venimos á palabras y á las manos, y habiéndome rompido una toca...

SIGÜENZA. ¡Ah, pese á la puta! ¿Por qué no me hallé presente?» (FERNÁNDEZ DE MoRATíN, 1830 : 430-431, las primeras réplicas del paso)

Las frases de Sigüenza representan todo lo contrario a lo que esperaríamos oír de un soldado fanfarrón. Es verdad que incluso en la boca de fanfarrones que se 
adecuen a las definiciones, encontraríamos galanterías verbales, pero en el caso de ellos, estas siempre quedan relativizadas por otras declaraciones del mismo protagonista, jactándose de sus victorias con las mujeres. Algo que aquí no encontramos.

Insistamos entonces en la explicación ya expuesta. Las características profesionales del rufián se basan en otras cualidades diferentes a la irresistible atracción por parte las mujeres. Si los fanfarrones grecolatinos se jactaban de la multitud de mujeres que mueren de amor por ellos, ${ }^{8}$ la construcción de estos personajes y su función en la trama en la comedia grecolatina llevaba una diferente lógica y por lo tanto, para el rufián español es superfluo buscar este tipo de fanfarronería. Aunque siempre debemos recordar que esta ausencia no influye en ningún caso en el punto de ridiculización del protagonista por la mujer, que está presente incluso en el caso del rufián. Esto lo veremos más adelante.

Ahora bien, una vez expuestas las características de la jactancia, continuemos con el posterior desenmascaramiento necesario del protagonista. En este caso, Sigüenza aparece como un perfecto fanfarrón cumpliendo con ambos elementos de su definición.

Examinemos primero la ridiculización de sus supuestas calidades militares y de su valentía en general. Tal como es habitual, la cobardía del fanfarrón se manifiesta rotundamente en el momento en el que entra en escena su antagonista, en nuestro caso Estepa (también lacayo según la cabecera del paso y muy probablemente también un rufián):

«SEBASTIANA. Oye, que Estepa viene.

SIGÜENZA. Por tu vida ten, tenme esta espada.

$[\ldots]$

ESTEPA. Agradesce que estás sin espada.

SEBASTIANA. Tómala, Sigüenza.

SIGÜENZA. Quítamela delante, diablo, que yo la tomaré cuando menester sea.» (FERNANDEZ DE MORATín, $1830: 435$ )

«ESTEPA. Dejémonos de gracias, doña bruta, andrajo de paramento; y vos, don ladron, tomá vuestra espada.

SIGÜENZA. Que no es mía, señor, que un amigo me la dejó con condición que no riñese con ella.» (FERNÁNDEZ DE MORATín, 1830 : 436)

«SIGÜENZA. Haré cuanto vuesa merced mandare.

ESTEPA. Que me deis la espada.

$[\ldots]$

SIGÜENZA. Dádsela [la espada], señora Sebastiana, por amor de Dios.

ESTEPA. Espera, que por fin y remate habéis de recibir de la mano de vuestra amiga tres pasagonzalos en esas narices bien pegados.

SIGÜENZA $a$. Señor, por amor de Dios, si puede ser, no sean pasagonzalos, sean pasarodrigos.

\footnotetext{
${ }^{8}$ En el Miles gloriosus encontramos un pasaje de esta índole, aunque de intensidad un poco más modesta: «Artotrogo [a Pirgopolinices]. Nada, ¿a qué voy a venirte yo a contar lo que todo el mundo sabe, esto es, que tú, Pirgopolinices, eres un ser único en el mundo por tu valentía, tu beldad y tus hazañas? Todas las mujeres se enamoran de ti, y no sin razón, puesto que eres tan guapo; como aquellas que me tiraban ayer de la capa.» (Plauto Tito Macio (1996), Comedias II, Madrid, Gredos, p. 314.)
} 
ESTEPA. Sus, arrodillaos, porque mas devotamente los recibais.» (FERNÁNDEZ DE MORATín, 1830: 437-439)

En estos tres pasajes discontinuos de las escenas, vemos perfectamente representada la naturaleza cobarde de Sigüenza. Primero, con la obvia intención de evitar la pelea, pasa su espada a Sebastiana tan pronto como ve a Estepa. A continuación, trata de utilizar este hecho para ofrecer una serie de excusas infantiles $\mathrm{y}$ al final sucumbe ante el enemigo sin pelear, entregándole la espada y soporta pacientemente (como veremos) los golpes a los que Estepa le condenó. Además, es la misma Sebastiana quien se las da.

Lo que nos lleva al segundo y último elemento del desenmascaramiento del fanfarrón, ser burlado por la(s) mujer(es). A pesar de las ausentes jactancias de éxitos galantes, como ya hemos dicho, Sigüenza aparece aquí como un fanfarrón perfecto. $\mathrm{Su}$ ridiculización con respecto del «amor» y relaciones con las mujeres está bien simbolizada por la falta de lealtad de su «amiga», y por su propio comportamento. Veamos la continuación de la escena final del paso, en el momento en el que la hemos dejado en la cita precedente y sigamos la hasta la última réplica, para que podamos comprobar el resultado y las consecuencias a los que llevó lo antes referido:

«SIGÜENZA. Ya estoy, señor, arrodillado; haga de mí lo que se le antojare.

ESTEPA. Ea, dueña, ¿qué aguardais? Dale recio.

$S I G \ddot{U E N Z A . ~ ¡ O h ! ~ P e ́ s e t e ~ a ́ ~ q u i e n ~ m e ~ v i s t i o ́ ~ e s t a ~ m a n ̃ a n a . ~}$

ESTEPA. Tené tieso ese pescuezo.

$S I G U ̈ E N Z A$. Señora Sebastiana, miserere mei, pasito, no tan recio.

ESTEPA. Bien está, dejadlo, para quien es, venios conmigo.

SIGÜENZA. La moza se me lleva. ¡Ah, Sigüenza, Sigüenza! igual fuera no desdecirte, y reñir de bueno a bueno con este Estepilla, y no quedaras sin honra y despojado de moza, y harto de pasarodrigos. ¡Ay narices mías que aún me duelen! Sus, en seguimiento me voy de mi Sebastiana.» (FERNÁNDEZ DE MORATíN, $1830:$ 438-439)

Notémonos bien que Sebastiana no interfiere verbalmente en el diálogo final entre Sigüenza y Estepa, y nos enteramos de la actitud de ella solamente a través de los dos antagonistas. Sin embargo, de las réplicas de ambos podemos reconstruir perfectamente lo que sucede. Es precisamente Sebastiana quien ejecuta las órdenes de Estepa, y le pega golpes «de recio» a Sigüenza. Y no solamente esto. Estepa le propone dejar a Sigüenza y unirse con él, y como deducimos de las palabras de Sigüenza, ella efectivamente parte con Estepa sin ningún comentario o reparo hacia su «amigo». Un detalle que ahonda aún más en ridiculización del protagonista, la cual llega a su culminación con la última réplica que cierra todo el paso. Sigüenza queda humillado por su antagonista, golpeado por su propia «amiga», la cual le abandona sin despedirse de él y, a pesar de todo esto, el antes jactancioso (¿y fingido?) matón sale en «seguimiento» de ella. ¿Nos podemos imaginar una situación más ridícula en la que pueda encontrarse un fanfarrón burlado?

Así creemos que Sigüenza en el paso llamado El Rufián cobarde se nos presenta como una de las pocas realizaciones que siguen muy de cerca las definiciones establecidas del arquetipo del soldado fanfarrón en el teatro español del siglo XVI. Nos podríamos aventurar a declararlo incluso como uno de los más «perfectos» 
fanfarrones de las tablas españolas de dicho siglo. Y si nos ceñimos a las fechas anteriormente propuestas para la datación del paso, lo podríamos señalar no solamente como uno de tantos, sino como precisamente el primer fanfarrón que cumple (con la ausencia de la discutida jactancia sobre el atractivo por parte de las mujeres) de sobras con la definición del tipo. Y esto no es poco afirmar, vista la complejidad de las modificaciones que los personajes del teatro del XVI presentan. En total, el personaje de Sigüenza lleva varias posibles primacías en su categoría, cuya fijación más profundamente argumentada requeriría una visión general amplia y al mismo tiempo pormenorizada de todos los géneros del teatro español de los siglos XVI y XVII. Un trabajo que todavía queda por hacer.

\section{BIBLIOGRAFÍA}

\section{Textos}

COTARElo Y MORI Emilio (1911), Colección de entremeses, loas, bailes, jácaras y mojigangas desde fines del siglo XVI a mediados del XVIII, tomo I, volumen I, Madrid, Casa editorial Bailly et Baillière, p. 76-79.

FERNÁNDEZ DE MORATÍN Leandro (1830), Orígenes del teatro español, tomo I, parte segunda, Madrid, Aguado, impresor de Cámara de S.M. y de su Real Casa, p. 430-439.

Lope De RuedA (1981), Pasos completos, prólogo de F. García Pavón, Madrid, Taurus, p. 127-135.

LOPE DE RUEDA (1908), Pasos completos, ed. de E. Cotarelo y Mori, Madrid, RAE. Registro de Representantes por Lope de Rueda y otros (1917), publicado por A. Bonilla y San Martín, Madrid, Ruiz hermanos, editores, p. 113-127.

Plauto Tito Macio (1996), Comedias II, Madrid, Gredos, p. 312-313.

\section{Estudios}

Boughner Daniel C. (1940), Don Armado and the Commedia dell'Arte, Studies in Philology 37, pp. 201-224.

Boughner Daniel C. (1943), The Braggart in Italian Renaissance Comedy, PMLA 58 (1), p. 42-83.

Boughner, Daniel C. (1954), The Braggart in Renaissance Comedy. A Study in Comparative drama from Aristoteles to Shakespeare, Minneapolis, The University of Minnesota Press.

CRAWFORD J. P. Wickersham (1911), The Braggart Soldier and the Rufián in the Spanish Drama of the Sixteenth Century, Romanic Review 2, p. 186-208.

DE MiCHELE Fausto (1999), Il guerriero ridicolo e la sua storia, ovvero dal comico sovversivo alla maschera vuota, Quaderni d'italianistica 20.1-2, p. 7-20.

DiAgo Manuel V. (1990), Lope de Rueda y los orígenes del teatro profesional, Criticón 50, p. 41-65.

FERNÁNDEZ FERNÁNDEZ Olga (2003), La comedia de figurón de los siglos XVII y XVIII, Madrid, Universidad Complutense, Servicio de Publicaciones [tesis doctoral de 1999].

LIDA DE MALKIEL María Rosa (1957), El fanfarrón en el teatro del Renacimiento, Romance philology 11, p. 268-291. 
LINCOLN G. L. (1910), Golondrino y Calandria: An inedited entremés of the Sixteenth century, Romanic Review 1 (1), p. 41-49.

MARTÍNEZ LÓPEZ María José (1997), El entremés : radiografía de un género, Toulouse, Presses Universitaires du Mirail.

MazzuCATo Tiziana (2007), „Lo Spagnuolo” : el cañamazo de un figurón de novelas (El carácter del capitán español de la Comedia del Arte y su transposición a la ficción narrativa), in : VEGA GARCÍA-LUENGOS Germán, GONZÁLEZ CAÑAL Rafael (eds.), Locos, figurones y quijotes en el teatro de los Siglos de Oro. Actas selectas del XII Congreso de la Asociación Internacional de Teatro Español y Novohispano de los Siglos de Oro, Almagro, 15-17 de julio de 2005, p. 315-324.

MiLANI Virgil I. (1965), The Origins of the Spanish Braggart in Strozzi's Commedia Erudita, Italica 42, no. 3, p. 224-230.

MORENO HERnÁNDEZ Antonio (2007), Tras la estirpe de los figurones : en torno al „miles gloriosus” de Plauto, in : GARCíA LORENZO Luciano (ed.), El figurón. Texto y puesta en escena, Madrid, Fundamentos, p. 23-70.

PROKOP Josef (2019), La definición del soldado fanfarrón en el teatro español de los siglos XVI-XVII, in : STROSETZKI Christoph (coord.), Perspectivas actuales del hispanismo mundial. Literatura - cultura - lengua. Volumen I: Medieval / Siglo de Oro / Teatro, Wissenschaftliche Schriften der WWU Münster, Reihe XII, Band 22.1., Münster, p. 373-381.

PROKOP Josef (2018), El muchacho llamado Golondrino: ¿un soldado fanfarrón?, in : HotaŘOVÁ, Liana (ed.), Pasión por el Hispanismo III, Liberec, Universidad Técnica de Liberec, p. 163-177.

PROKOP Josef (2013), El arquetipo de soldado fanfarrón - aportación española a la literatura mundial, in : DEMLOVÁ Jana, MíčA Slavomír (eds.), Héroe y antihéroe en las literaturas hispánicas, Liberec, Universidad Técnica de Liberec, p. 23-43.

SÁNCHEZ JIMÉNEZ Antonio (2012), Fanfarronería española en „La contienda de García de Paredes y el capitán de Juan de Urbina" : Lope de Vega ante la Leyenda Negra, in : PEdRAZA JimÉnEZ Felipe B., GonZÁlez CAÑAL Rafael, MARCELLO Elena E. (coord.), Europa (historia y mito) en la comedia española : XXXIII Jornadas de Teatro Clásico, Almagro, 6, 7 y 8 de julio de 2010, Universidad de Castilla-La Mancha, Ediciones de la Universidad de Castilla-La Mancha, p. 83-98.

SÁNCHEZ JiMÉNEZ Antonio (2007), Del miles gloriosus al figurón : los orígenes de la comedia de figurón en La contienda de García Paredes y el capitán Juan de Urbina (1600) de Lope de Vega, in : GARCÍA LORENZO Luciano (ed.), El figurón. Texto y puesta en escena, Madrid, Fundamentos, p. 107-127.

Senigaglia Graziano (1899), Capitan Spavento, Firenze, Bernardo Seeber. 